\title{
SEEING TO IT THAT THE SUBJECT OF THE SCIENCE IS THE SUBJECT OF ITS PRACTICE: TOWARD A THEORY OF THE OUTCOME OF AN ECONOMIC SYSTEM'S WORKING*
}

\author{
Rutledge Vining**
}

\section{I}

Analogies with and terms of medical science and practice seem to come naturally to economists in their thought and expressions. I shall later elaborate upon one that looks to be pertinent for this occasion. Briefly stated, there are these aspects of it: each science, as I suppose all applied sciences, had its rise in the practice of quasiprofessional practitioners; in the practice of each the subject is a real object whose observed state is liable to aberrancy; the practitioners of each treat with, at least professionally talk about, mechanisms that work well or else ill in some degree. But there is this notable contrast: One can scarcely conceive of the possibility of medical science getting off or being off its track-in the sense of its identifying and primary subject of study becoming something other than the basic subject of the practice. But this is not the case at all with the science of economics. The history of it has long been marked by active controversy respecting what the scientific subject is. The primary subject of the practice is what it ever has been: that immense physical reality whose observed state is subject to being aberrant; and those oft-cited mechanisms that are said to be working well or else not. But in contrast to the way things are in the practice and science of medicine, this real object and those mechanisms are not nearly so directly before one's eyes. A certain technical competence is required for even identifying and comprehending what they actually are in fact. And the science of economics has somehow come to be not altogether and foursquarely on the track - to the extent that, apart from certain offerings in Centers of Population Studies and Departments of Regional Science, the basic subject of the practice is virtually missing from the subjects treated in the science.

Hence my title; and hence my choice for this occasion of this topic of discussion.

\section{II}

Adam Smith called it "the science of the legislator." His book upon the subject, The Wealth of Nations, had its

\footnotetext{
*This article was originally presented as a fellow address at the 25th meeting of the Southern Regional Science Association, March 6-8, 1986 in New Orleans, Louisiana.

**The author is professor emeritus of economics at the University of Virginia, Charlottesville, Va.
}

origin as a section of his Lectures on Jurisprudence. Ricardo, Malthus, and Mill are instances of early practitioners; and throughout the history of the science, its leading figures have nearly all left records of their practice, either as legislators themselves, (Ricardo, Mill, Paul Douglas) or as specialist advisors to legislators (Marshall, Wicksell, Fisher, Keynes, Leontief, Schultz, Friedman).

Legislators are officially responsible for the outcome of the working of the economic system; and this-the outcome of the economic system's working-is the primary and identifying subject of the practice. Said Keynes, in the context of a case of his practice and with reference to the thing that is working: "We have involved ourselves in a colossal muddle, having blundered in the control of a delicate machine, the working of which we do not understand." Said Leontief, in a case of his practice and also with reference to the thing that is working: "Keeping the American economic system in good working ... order requires lifting the hood, observing and if necessary adjusting the operation of the moving parts of the engine, and replacing those that turn out to be defective. What the government and public need is a service manual describing gears, nuts, and bolts." These metaphorical expressionsthe "machine" the working of which we do not understand, the "engine" whose working parts may turn out to be defective, the "service manual" of which the public is in need-are vividly as well as accurately to the very point of the primary subject of the practice. It isn't uncommon at all that specialists speak in this manner about their subjects. I have heard medical scientists and practitioners use nearly the same metaphors in referring to the subjects of their research and practice. With them, if a listener be in doubt respecting what the reality is for which the metaphor is a fanciful name, he may be readily shown the thing itself or a picture or physical model of it. And it is precisely here that there is the striking difference mentioned earlier. With us, beyond the metaphors there is a void. The outcome of its working being what in actual fact it is-account being taken of the kind of things these are in which the outcome is manifested-a theory of the outcome of an economic system's working is altogether missing from the textbooks and teaching of the science of economics. A typical student of this science will not have acquired in his training the prerequisites for even recognizing or identifying what this "machine" or "engine" really is, not to mention making headway toward understanding the working of it. 
III

This of course would be disputed. Had Leontief been asked to go into some detail respecting the engine of which he spoke, one might confidently guess that he would have set forth some version of his own input-output model. Recalling the low assessment that Keynes put upon Tinbergen's model of an economic system, I am hesitant in speculating upon what Keynes would have expounded upon as the machine to which he referred. But there are all of those econometric models that are more or less founded upon his thought; and there are such closely associated specifications as Koopmans' in his "On the Description and Comparison of Economic Systems." Each model, including Leontief's, consists of a system of equations relating some collection of conventionally defined variables. In the higher reaches and purer forms of economic theorizing there is a similar kind of reduction of the "working" thing to a system of equations, and similar linguistic usage - as in the Hicksian "Laws of the Working of the System": system being the name of something that is working; this system being in fact a Walrasianlike system of equations; the laws, in the scientific sense of law, having been deduced as implications of certain postulated conditions specified in these equations.

But none of these will do; none fit the factual circumstances of the practice. The conception of a working system that such models represent is not the right one for the context of Keynes' and Leontief's remarks. It will have come from studies not specifically addressed to and focused upon the problems of the practice. None of these systems of equations are descriptive of the mechanism the outcome of the working of which legislators deliberate upon.

But then, how does one know this? How is one to tell what this "working" thing really is in fact?

\section{IV}

It is a matter first of all for empirical inquiry. Legislators in the very act of deliberating upon how well or ill a presently operating system is working - that is where one must go to find out what specifically it is that is working. The first step in one's identifying what it is that is working - in the factual set of circumstances of these deliberations-is that of determining and describing what the manifestations of the outcome of this working consist of what the particularities are that are conveying to responsible deliberators a sense of the working system's performance. The mechanism of the system would then be identified as that special kind of thing that generates in its working such particularities as are being reacted to. In a recently published book I have set forth what I think one will find to be the case in this regard. In any instance of these deliberations, the particularities to which the law choosers are reacting can be seen to be certain statistical properties of some one or another population process or some process of events. This is not to say that the legislators themselves use or think in such terms. But a practitioner of a special science so formed and focused as to be specifically applicable in this actual practice (i.e., in expertly describing what in fact is being reacted to and what then in fact the properties of this that is being reacted to depend upon) should be prepared to recognize this that the deliberators talk and become concerned about for what it really is. And what it is then, is a congeries of population processes and processes of events.

The manifestations of the outcome of this working thus being in the form of statistical properties of variables defined upon certain population processes, and economic system (Keynes' "machine," Leontief's "engine") being a name by which legislators designate the something that is doing this working (i.e., generating the variations that are characterized by these observed properties), it then would seem to follow that the working part of this system consists of a collection of statistical mechanisms, in precisely the sense in which natural scientists use this term. What it is that legislators are reacting to (i.e., that convey to them a sense of how well the something for which they are responsible is working) are statistical properties of population processes. Frequency functions-specifications of their shapes and forms-are the contrivances at hand for describing such statistical properties. The theory that is specifically applicable in an inquiry into what these properties depend upon is the theory of these frequency functions (i.e., of stochastic processes). An application would have as its objective a finding out of the statistical mechanisms that are in fact generating the variations described by the observed frequency functions. The theory that is applied in constructing the above mentioned modelsthose of Leontief, Koopmans, Hicks, and the rest-is not this kind of theory. Frequency functions-descriptive of the variations the properties of which legislators are in fact reacting to-are not what it is about. Its subject is the subject of the science as presented in the textbooks and treatises of economics; but the subject of the practice is something else: population processes and processes of events, whose statistical properties convey sense to legislators respecting how well the system "works."

The best way that has occurred to me for one's acquiring a firmer feel for what this means is to painstak- 
ingly try to describe, with as much detail and comprehensiveness as can be mustered, some population process the statistical properties of which do in fact convey to responsible observers this sense of how well the system "works." In the book mentioned just above I report the results of my students and myself trying to do this-describing as a population process, the employment state of this nation's population of people, dispersed as this population really is over the national area and developing as it actually did over an extended span of time when it was generally said to be in a state of full employment. And this illustrative exercise serves to demonstrate, I think, the kind of problems with which specialists will come to be involved in trying to find out what the generating mechanism is whose alteration would be required in order that the statistical properties of such a population process be changed in some predetermined respect. And there are these cardinal facts made evident: that there is no possibility whatever of legislators altering directly, by statutory decree or legislative fiat, the statistical properties of the variations that are conveying to them a sense of how well the system "works"; that there is no more possibility of their altering directly, by statutory decree or legislative fiat, the statistical mechanisms that are in fact generating the variations characterized by these statistical properties; that the choices actually exercised by legislators, with the intent of somehow altering the statistical properties in question, are rigidly restricted to systems of statutory law and administrative rule (i.e., the "rules of the game"); so that the analytical problem comes to be reduced to that of finding out (1) the statistical mechanisms that are in fact generating the variations whose properties convey the sense of performance, and (2) the dependence of these mechanisms, which are not subject to direct alteration, upon the "rules of the game," which are; and thus that the true and simple prototype of the theory of the subject of the practice is the olden theory of fair gamesthe theorist in each instance seeking knowledge of how to transform rules the outcome of whose working does not satisfy prescribed conditions to rules the outcome of whose working does. 